\title{
Antiphospholipid Antibody
}

National Cancer Institute

\section{Source}

National Cancer Institute. Antiphospholipid Antibody. NCI Thesaurus. Code C121327.

A class of autoantibodies directed against phospholipids or phospholipoproteins. Its presence may indicate an increased risk for hypercoagulability, pregnancy loss or autoimmune disease. 